\title{
Energy Consumption in the Process of Excavator-Automobile Complexes Distribution at Kuzbass Open Pit Mines
}

\author{
Ivan Panachev ${ }^{1, *}$, Boris Gerike ${ }^{1}$, Ilya Kuznetsov $^{1}$, Anastasia Shirokolobova ${ }^{1}$ \\ ${ }^{1}$ T.F. Gorbachev Kuzbass State Technical University, 650000, Kemerovo, 28 Vesennya st., Russian \\ Federation
}

\begin{abstract}
Every year worldwide coal mining companies seek to maintain the tendency of the mining machine fleet renewal. Various activities to maintain the service life of already operated mining equipment are implemented. In this regard, the urgent issue is the problem of efficient distribution of available machines in different geological conditions. The problem of "excavator-automobile" complex effective distribution occurs when heavy dump trucks are used in mining. For this reason, excavation and transportation of blasted rock mass are the most labor intensive and costly processes, considering the volume of transported overburden and coal, as well as diesel fuel, electricity, fuel and lubricants costs, consumables for repair works and downtime, etc. Currently, it is recommended to take the number of loading buckets in the range of 3 to 5 , according to which the dump trucks are distributed to faces.
\end{abstract}

\section{Introduction}

The increasingly complex operating conditions require the development of new assessment factor, which can take into account the maximum possible number of machine operating parameters (bearing capacity, bucket capacity, etc.).

The value of specific energy cost (SEC) for the transportation of 1 ton of rock mass from the open pit was accepted as the measuring energy efficiency factor of the deep pit transport systems, which was determined by the formula [1]

$$
P_{f}^{a}=\frac{g}{i} \times k_{n e p} \times k_{u T} \times k_{d},
$$

where $P_{f}^{a}$ - the specific energy cost for transportation of 1 ton of rock mass to $1 \mathrm{~m}$, g.s.f./t $\cdot \mathrm{m}$ (grams of standard fuel $/ \mathrm{t} \cdot \mathrm{m}) ; g-$ specific cost of diesel fuel by trucks, $\mathrm{g} / \mathrm{t} \cdot \mathrm{m} ; i-$ route inclination, $\% ; k_{\text {nep }}$ - the processing coefficient, considering energy costs to get diesel from oil $\left(k_{n e p}=1,18 \div 1,20\right) ; k_{d}$ - the coefficient, considering energy costs to produce and to transport fuel $\left(k_{d}=1,04 \div 1,10\right) ; k_{u T}$ - the coefficient, considering the difference of specific heat of diesel combustion and equivalent fuel $\left(k_{u m}=1,5\right)$.

\footnotetext{
${ }^{*}$ Corresponding author: pia.sm@yandex.ru
} 
It was estimated that the specific energy cost is substantially affected by such factors as dump truck overloading, route inclination on the rise and others [2].

Transportation of blasted rock mass by heavy dump trucks can be divided into energyconsuming and energy-conservation modes according to energy indicators.

Such steps of transportation as loading and unloading, waiting for loading, shift change, lunch break are related to energy-consuming. At these stages dump trucks movement is not observed, an engine runs at idling speed, therefore, there is no significant energy consumption [5]. Only operable conditions of the engine fuel system have impact on energy consumption. If the dump truck parts are in good condition, energy cost is valid.

The main influence on energy consumption of the transportation process and metalwork operation time occurs during energy-consuming stages of operation. These stages include the machine straight technological roads traffic, upgrades and descents, turnings and traffic through the crossings. However, it should be noted that each of the given traffic parameters corresponds to its value of energy demands.

As a result of analysis of the influence of various operating parameters of the open pit automotive transport on energy consumption of transportation process, it was determined that the longitudinal inclination of open pit roads is the most informative parameter of specific energy consumption evaluation [3].

\section{Results and Discussions}

According to the results of investigations carried out at Kuzbass open pits, the diagram of route inclination was designed; if to reach this inclination it is possible to observe a significant change in the operating terms of dump trucks with various bearing capacities (Figure 1).

Figure 1 shows typical route inclinations for the following operating parameters: $Q_{\text {nom }}-$ nominal value of diesel fuel consumption, at which the engine is operating at nominal power (engine life is not reduced, specified by the manufacturer); $\mathrm{P}_{\text {fnom }}$ - nominal value of specific energy cost, at which there is time to failure, stated by the manufacturer; $\sigma_{\text {nom }}$ nominal stresses in suspension mount of metalworking that are equal to endurance limit, at which cracks formation and growth are not yet observed; $\mathrm{P}_{\text {fpre }}$ - limit volume of unit costs, at which the time to failure is $20 \%$ from guaranteed by the manufacturer.

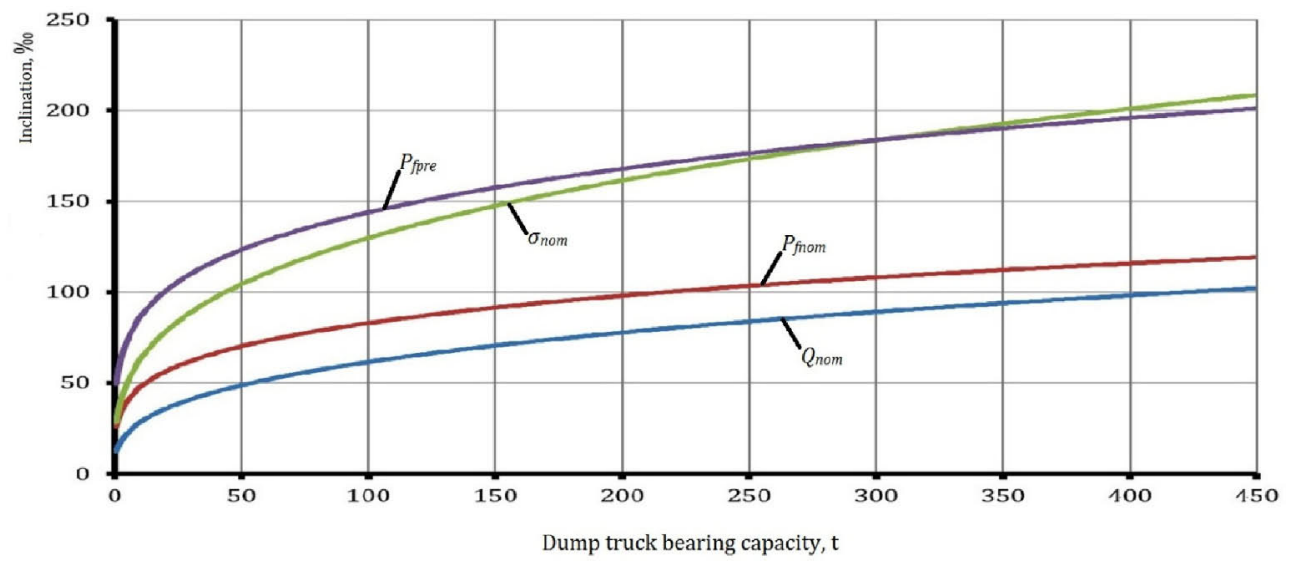

Fig. 1. The diagram of specific route inclinations

Figure 1 shows that the curves $\mathrm{Q}_{\text {nom }}$ and $\mathrm{P}_{\text {fnom }}$ are parallel in all the diagram area; and if to calculate the specific energy cost the consumption of diesel fuel is to be taken into account (see formula 1). For the dump trucks with bearing capacity from 250 to $350 \mathrm{t}$ on 
the route inclinations from 170 to $190 \%$ o the identical operating conditions influence on the values of marginal energy costs and nominal voltages in the load-bearing steel structures are observed. Moreover, the extreme point (350 t; $190 \%$ ) of intervals is characterized by increased stress and, consequently, reduction of structural life of heavy trucks.

In this regard, when choosing motor transport to use in developed deposits to the value of the longitudinal inclination of $190 \%$, it is necessary to be based on the change of specific energy cost, and if the value of the longitudinal inclination is more than $190 \%$ it is necessary to be based on the change of nominal voltages.

The analysis of the results allowed to get the dependence of the specific energy cost on mined rock transportation from dump truck bearing capacity. Figure 2 shows the diagram of the established relationship for heavy trucks at longitudinal inclinations from $10 \%$ to $100 \%$.

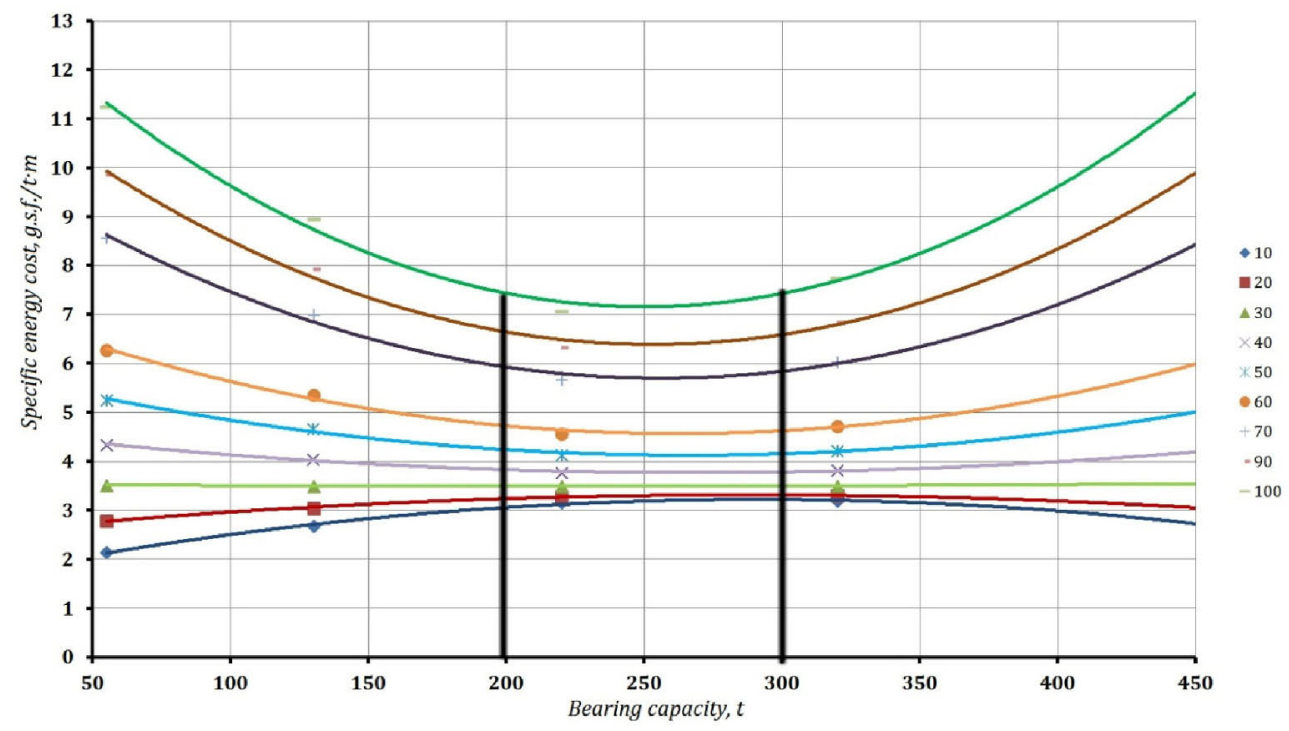

Figure 2. The dependence of the specific energy cost for transportation on dump truck bearing capacity

Figure 2 shows that the most universal indicator of energy efficiency for usage in different mining geological and technical conditions are dump trucks with bearing capacity of 200-300 t. The value of SEC is taken for the energy efficiency estimation test of excavation process [4]:

$$
P_{f}^{e}=w \times k_{e} \times k_{\text {loss }} \times k_{d},
$$

where $P_{f}^{e}-$ the specific energy cost for excavation of $1 \mathrm{~m}^{3}$ of rock mass, g.s.f./t $\cdot \mathrm{m}$ (grams of standard fuel $\left./ \mathrm{m}^{3}\right) ; w$ - specific energy consumption by an excavator, $\mathrm{kW} \cdot \mathrm{h} / \mathrm{m}^{3} ; k_{e}-$ the coefficient considering energy costs to produce $1 \mathrm{~kW} \cdot \mathrm{h}$ of electricity $\left(\mathrm{k}_{3}=310 \div 330\right.$ $\mathrm{g} / \mathrm{kW} \cdot \mathrm{h}) ; k_{\text {loss }}$ - the coefficient considering losses of electricity under transmission and distribution $\left(\mathrm{k}_{\text {loss }} \approx 1,09\right) ; k_{\partial}$ - the coefficient considering the cost of energy under fuel extraction and transportation $\left(k_{\partial}=1,04 \div 1,10\right)$. Specific energy consumption by an excavator is the ratio of electricity cost $(\mathrm{E})$ to the machine technical performance per hour $\left(\mathrm{P}_{\text {tech }}\right)$ :

$$
w=E / P_{\text {tech }} \text {. }
$$

The technical performance per hour is calculated by the formula: 


$$
P_{\text {tech }}=\frac{3600 E}{T_{\text {w.c. }}} \times k_{e x} \times k_{f}
$$

where $E$ - bucket capacity, $\mathrm{m}^{3} ; T_{w . c .}$ - the duration of excavation working cycle, $\mathrm{s} ; k_{e}-$ the excavation coefficient; $k_{f}$ - the face coefficient considering the effect of auxiliary operations.

JSC "Berezovskiy" (Prokopyevsk) was chosen as an experimental base, where a large number of excavators used are the excavators with a shovel capacity of $5 \mathrm{~m}^{3}$ (ECG-5), 10 $\mathrm{m}^{3}$ (ECG-10) and $12 \mathrm{~m}^{3}$ (ECG-12), the dependences of the specific energy cost on excavation from the dump truck bearing capacity (respectively) were estimated (see Fig. 3):

$$
\begin{aligned}
& P_{f}^{e}=0.0024 q^{2}-0.2857 q+168.401, \\
& P_{f}^{e}=0.0015 q^{2}-0.1252 q+154.977, \\
& P_{f}^{e}=0.0015 q^{2}-0.1514 q+154.875 .
\end{aligned}
$$

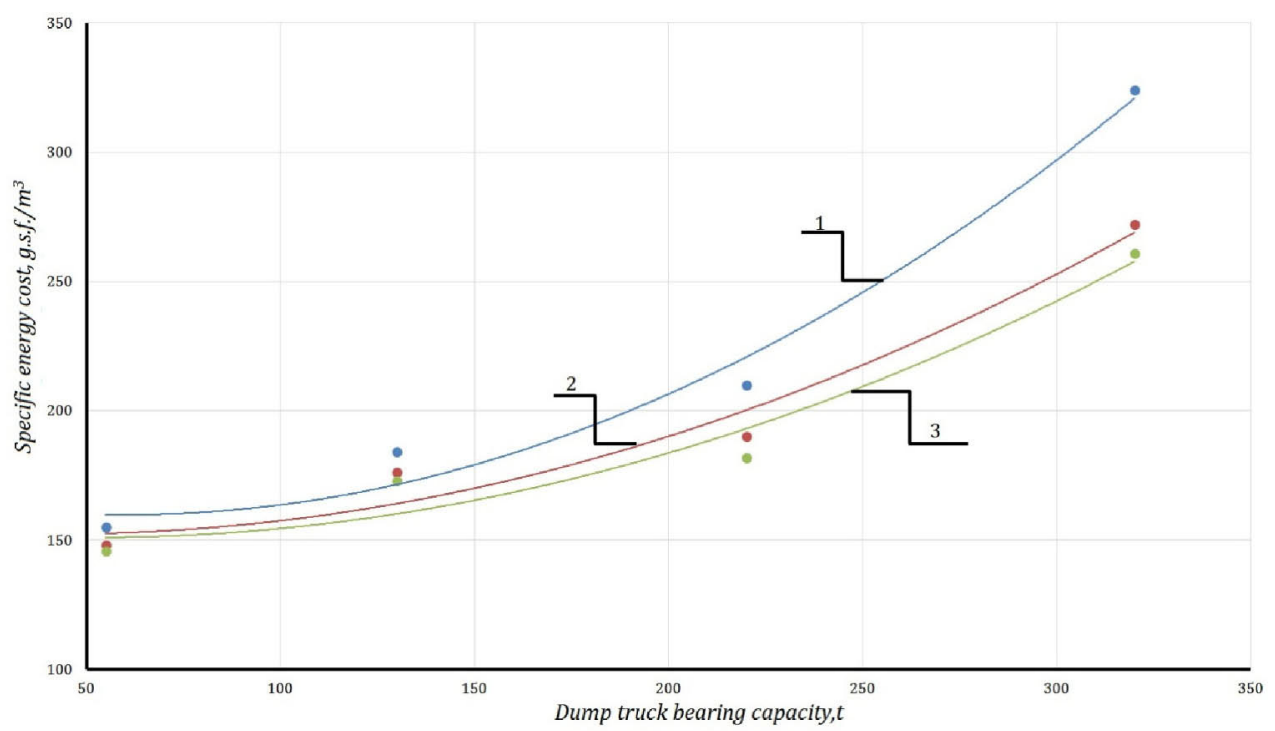

Figure 3. The dependence of specific energy cost of excavators with bucket capacity 5,10 and $12 \mathrm{~m}^{3}$ on excavator bearing capacity (1 - ECG-5, 2 - ECG-10, 3 - ECG-12)

Figure 3 shows that the areas of dependency in the range of 50 to $130 \mathrm{t}$ are maximum close to a straight line; it indicates a slight increase in the share of energy cost due to the recommended amount of bucket loading. Further there is a substantial increase in energy consumption of the excavator with bucket capacity of $5 \mathrm{~m}^{3}$. Consequently, the greater the deviation from the recommended amount of bucket loading is, the higher the jump in specific energy cost is. For the energy assessment of dump trucks distribution with an excavator ECG-10, a joint diagram of dependences of specific energy cost by excavatorautomobile complex on dump trucks bearing capacity in operation at the maximum permissible longitudinal inclination of pit roads in $80 \%$ was built (Fig. 4). 


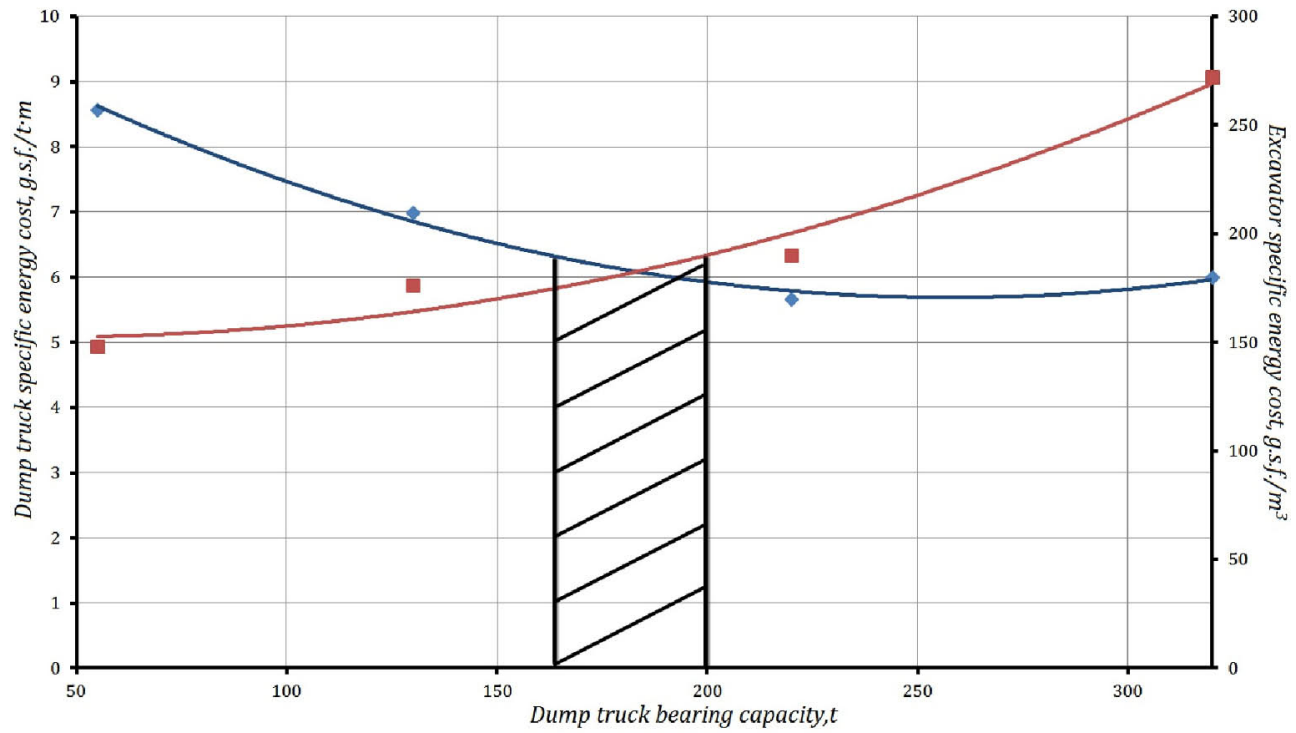

Figure 4. The dependences of specific energy cost of excavator-automobile complex on dump truck bearing capacity

Figure 4 shows that heavy dump trucks with carrying capacity of 160-200 t are the best and most effective in operation for the ECG-10 excavator according to energy parameters. In this case, the unit cost of the dump truck and the excavator are as close to their lowest values. Thus, the number of buckets loading varies from 6 to 9 .

\section{Conclusions}

When calculating the dump truck bearing capacity corresponding to the recommended number of loading buckets (3-5), it was estimated that dump trucks with bearing capacity up to $130 \mathrm{t}$ are the most effective for ECG-10 excavators. However, specific energy cost for transportation in this case takes rather high value (1.2-1.5 times higher than in energy selection of excavator-automobile complex), which has a negative impact on all the parameters of motor transport operation. According to the research results, it was estimated that energy assessment of the operational efficiency of excavator-automobile complex, based on specific energy cost, is a multi-factor characterizing fundamental parameters of the excavators and dump trucks operation in the developed deposit conditions; and it is recommended to be used when excavator-automobile complex is being chosen.

\section{References}

1. I.A. Panachev, G.V. Shirokolobov, I.V. Kuznetsov, A.G. Shirokolobova, 8th RussianChinese Symposium. Coal in the 21st Century: Mining, Processing and Safety, 144 (2016)

2. I.A. Panachev, I. V. Kuznetsov, Journal of Mining Science, 51, 267 (2015)

3. Baoying Fan, Yingju Yuan, Int. Journal of Mining Science and Tech., 26, 653 (2016)

4. A. Soofastaei, S.M. Aminossadati, Int. J. of Min. Sci. and Tech., 26, 745 (2016)

5. I. V. Sokolov, A. A. Smirnov, Yu. G. Antipin, J. of Mining Science, 52, 121 (2016)

6. V.A. Solomennikov, V.I. Cheskidov, Journal of Mining Science, 51, 1213 (2015) 
7. S.V. Klishin, A.F. Revuzhenko, Journal of Mining Science, 51, 1070 (2015)

8. Chengguo Zhang, Ismet Canbulat, Faham Tahmasebinia, Bruce Hebblewhite, International Journal of Mining Science and Technology, 27, 43 (2017)

9. Fukun Xiao, Gang Liu, Ze Zhang, Zhiliang Shen, Fengrui Zhang, Yifei Wang, International Journal of Mining Science and Technology, 26, 981 (2016)

10. J. Jiang, Q. Liu, J. Xu, Int. Journal of Mining Science and Technology, 26, 1003 (2016)

11. Jesse W. Puller, Ken W. Mills, Rob G. Jeffrey, Rick J. Walker, International Journal of Mining Science and Technology, 26, 103 (2016)

12. V.P. Efimov, Journal of Mining Science, 52, 274 (2016)

13. S. Bornyakov, D.V. Salko, Journal of Mining Science, 52, 338 (2016)

14. Yu. V. Lesin, S.Y. Luk'yanova, M.A. Tyulenev, J. Min. Sc., 46, 78 (2010)

15. E.N. Sher, V.P. Efimov, Journal of Mining Science, 51, 1108 (2015) 